
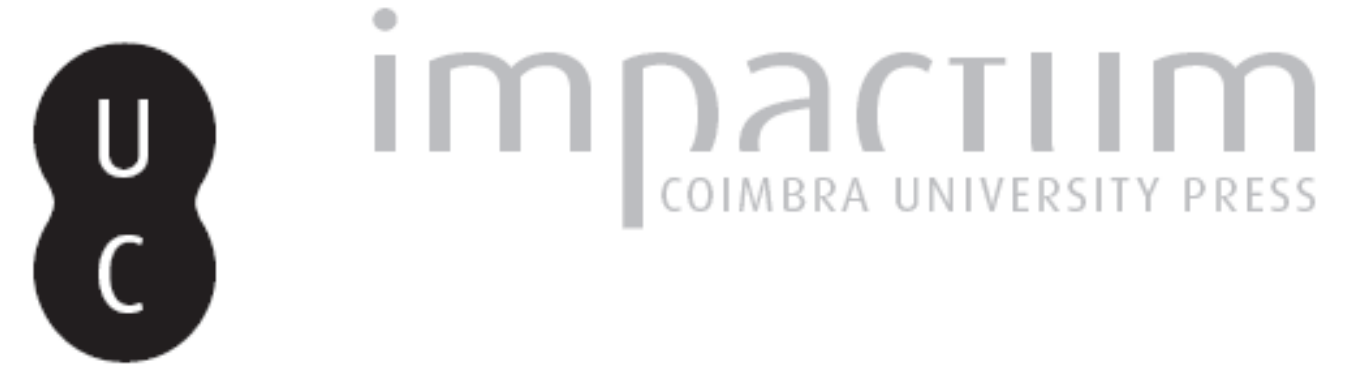

\title{
Relevância informativa das despesas de investigação e desenvolvimento: um estudo para o caso português
}

Autor(es): $\quad$ Cunha, Ana; Moreira, José António

Publicado por: Faculdade de Economia da Universidade de Coimbra

URL

persistente:

URI:http://hdl.handle.net/10316.2/25230

DOI:

DOI:http://dx.doi.org/10.14195/2183-203X_31_1

Accessed : $\quad$ 26-Apr-2023 14:56:10

A navegação consulta e descarregamento dos títulos inseridos nas Bibliotecas Digitais UC Digitalis, UC Pombalina e UC Impactum, pressupõem a aceitação plena e sem reservas dos Termos e Condições de Uso destas Bibliotecas Digitais, disponíveis em https://digitalis.uc.pt/pt-pt/termos.

Conforme exposto nos referidos Termos e Condições de Uso, o descarregamento de títulos de acesso restrito requer uma licença válida de autorização devendo o utilizador aceder ao(s) documento(s) a partir de um endereço de IP da instituição detentora da supramencionada licença.

Ao utilizador é apenas permitido o descarregamento para uso pessoal, pelo que o emprego do(s) título(s) descarregado(s) para outro fim, designadamente comercial, carece de autorização do respetivo autor ou editor da obra.

Na medida em que todas as obras da UC Digitalis se encontram protegidas pelo Código do Direito de Autor e Direitos Conexos e demais legislação aplicável, toda a cópia, parcial ou total, deste documento, nos casos em que é legalmente admitida, deverá conter ou fazer-se acompanhar por este aviso.

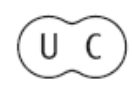




\section{N $\odot$ TASEC $\odot$ N}

\section{ANA CUNHA / JOSÉ RELEVANCIA INFORMATIVA DAS DESPESAS DE INVESTIGAÇÃO E DESENVOLVIMENTO: ANTÓNIO MOREIRA RELEVANCIA INFORMATIVA DAS DESPESAS D
UM ESTUDO PARA O CASO PORTUGUÊS}

MARIA ANTÓNIA JESUS / FROM GOVERNMENTAL ACCOUNTING TO NATIONAL ACCOUNTING: IMPLICATIONS ON SUSANA JORGE THE PORTUGUESE CENTRAL GOVERNMENT DEFICIT 


\section{6 (III) (O) Relevância informativa das Despesas de Investigação 7 e Desenvolvimento: um estudo para o caso português}

Ana Cunha / José António Moreira FEP/FEP-CEF.UP - Universidade do Porto

resumo

O presente estudo procura aferir, para o contexto português, a relevância

informativa das despesas de I\&D. A

metodologia adoptada assenta no uso de modelos econométricos, que tiveram em consideração a natureza da informação disponibilizada pelas empresas e a adopção em $\mathbf{2 0 0 5}$ das denominadas normas internacionais de contabilidade.

A evidência empírica recolhida sugere que os investidores avaliam positivamente a informação sobre I\&D. De modo particular, a informação de natureza quantitativa relativa à capitalização das despesas de I\&D; em menor grau, a informação de natureza qualitativa. Aliás, o valor incremental desta última tende a ser nulo quando se consideram nos modelos, em simultâneo, ambos os tipos de informação.

A alteração do normativo contabilístico em 2005 parece ter tido impacto na relevância informativa das despesas de I\&D, aumentando-a. Principal explicação para tal evolução parece ser o carácter mais restritivo que tais normas impuseram para a capitalização dessas despesas no período pós-2005. résumé / abstract

This study tests the value relevance of $R \& D$ expenses for the Portuguese context. The methodology adopted is based on econometric models, and takes into consideration the kind of information companies display and the adoption of IASB accounting standards in 2005.

The empirical evidence suggests that investors value positively R\&D information, most especially when it is quantitative and relates to the capitalisation of such expenses. Their value relevance is less obvious when the information is qualitative, and vanishes completely when both types of information are considered simultaneously in the models.

The change in the accounting environment in 2005 seems to affect the empirical evidence. It suggests that a higher restrictiveness of IASB standards on concerning the capitalization of R\&D justifies the increase in the value relevance of the expenses capitalized in 2005 and afterwards.

Classificação JEL: M41, C23, G12 
A informação sobre as actividades de Investigação e Desenvolvimento (I\&D) levadas a cabo pelas empresas é apresentada na literatura como sendo muito importante para os investidores. Autores como Sougiannis (1994) e Lev e Sougiannis (1999), entre outros, referem que a actividade de I\&D está fortemente associada com ganhos futuros de produtividade das empresas e, por inerência, com os resultados que elas virão a reportar. Não admira, pois, que tal informação seja importante para os investidores, já que lhes permite formular expectativas mais precisas sobre a evolução do valor das empresas.

A literatura anglo-saxónica corrobora tal importância mostrando que, embora contabilisticamente as despesas de I\&D sejam tratadas como um gasto do exercício, afectando negativa e imediatamente os resultados do período, os investidores tendem a valorá-las positivamente quando avaliam as empresas, o que significa que as consideram como um activo intangível (e.g. Hirschey, 1982; Hirschey e Weygandt, 1985) que gerará benefícios económicos futuros.

Ciclicamente, sempre que o desenvolvimento da economia portuguesa se torna tema de debate, é comum ouvir dizer-se que o país precisa de investir em factores produtivos de natureza intangível, o que supõe, da parte das empresas, a afectação de parte dos seus recursos a actividades de investigação e desenvolvimento. Este argumento, não contraditado, tem como contraponto o desconhecimento que existe sobre esse tipo de investimento e sobre as respectivas consequências para a economia. Uma das razões para tal situação, que se traduz na muito escassa produção científica sobre o tema, tem por base a falta de divulgação por parte das empresas dos montantes investidos em I\&D.

O enquadramento contabilístico assente no POC - Plano Oficial de Contabilidade e nas DC Directrizes Contabilísticas não as obrigava a tal, o que significa que a pouca informação disponibilizada tinha carácter de divulgação voluntária. Portanto, embora as regras de contabilização assentes naquele normativo não se distingam sobremodo das que afectam as empresas dos países anglo-saxónicos, as obrigações de divulgação são completamente diferentes, sendo as empresas nestes países obrigadas à revelação anual dos montantes de despesas de investigação e desenvolvimento contabilizados como gastos.

A falta desta informação condiciona os investigadores em Contabilidade e em Finanças, mas condiciona igualmente os investidores, que não conseguem, na generalidade dos casos e a partir do relatório e contas da empresa, ter uma percepção adequada dos gastos em despesas de I\&D por ela efectuados.

Neste domínio, a situação está a alterar-se ou, pelo menos, tem condições para se alterar. As empresas portuguesas cotadas que adoptaram as normas internacionais de contabilidade (NIC) do IASB - International Accounting Standard Board, por via da norma IAS 38, estão obrigadas a divulgar, a partir de 2005 , os dispêndios com a actividade de $1 \& D^{1}$. As restantes empresas, por via da adopção do novel SNC - Sistema de Normalização Contabilística, que vem substituir o POC/DC, serão igualmente obrigadas a tal divulgação a partir de 2010. Aliás, já o deveriam ter feito a partir de 2007, com base no despacho n. ${ }^{\circ}$ 9028/2007 da Comissão de Normalização Contabilística, que estipula os termos em que tal divulgação deve ser efectuada. Portanto, para futuro, todas as empresas deverão divulgar informação sobre as despesas associadas às respectivas actividades de I\&D.

Antecedendo esse futuro, o objectivo genérico do presente estudo é avaliar, para as empresas não financeiras portuguesas cotadas na Euronext Lisbon que divulgam algum tipo de informação sobre as suas actividades de I\&D, se a mesma é utilizada pelos investidores e reflectida na avaliação que fazem das empresas. Ou seja, o estudo analisa a relevância informativa daquela informação. 
Tendo em consideração a evidência empírica disponível na literatura, versando particularmente o contexto anglo-saxónico, espera encontrar-se uma relação positiva entre a existência de actividades de I\&D e o valor de mercado das respectivas empresas, consistente com a ideia acima apresentada de que tais actividades contribuem para gerar benefícios económicos futuros. Os resultados recolhidos no presente estudo são genericamente consistentes com aquela literatura, de modo particular no período pós-2005, sugerindo que existe uma avaliação positiva das despesas de I\&D pelos investidores. Ou seja, o mercado tende a reconhecer estas despesas como um activo com impacto positivo nos cash-flows futuros. À semelhança doutros estudos (e.g. Aboody e Lev, 1998; Callimaci e Landry, 2004; e Oswald e Zarowin, 2007), a informação de cariz numérico sobre as despesas de desenvolvimento capitalizadas tende a apresentar maior relevância que a informação de natureza qualitativa.

A estrutura do trabalho é a seguinte. O Capítulo 2 discute a literatura relevante para o estudo. O Capítulo 3 apresenta o estudo empírico e discute os respectivos resultados. Finalmente, o Capítulo 4 apresenta a conclusão, onde se sistematizam os principais resultados e contribuições.

\section{Revisão de literatura relevante}

A literatura sobre a relevância valorativa da actividade de I\&D tem por base, essencialmente, a realidade anglo-saxónica e as empresas dos Estados Unidos e do Reino Unido. Para compreender esta concentração espacial ter-se-á que ter em conta que tais empresas são obrigadas a divulgar o montante dos seus gastos de I\&D no período e, por isso, essa informação está disponível para os investigadores. Isso explicará, pelo menos em parte, que mesmo investigadores portugueses devotem o melhor do seu esforço a investigar essa realidade espacial (e.g. Nascimento, 2007).

As três secções seguintes revêem a literatura nos ramos de investigação mais directamente relacionados com o objectivo do presente estudo, i.e. a relevância informativa, a relevância de informação não financeira e o impacto sobre tal relevância derivado de diferentes tratamentos contabilísticos dados às despesas de I\&D.

\subsection{Relevância informativa das despesas de I\&D}

Este ramo de investigação tem centralizado ao longo das últimas décadas a maior parte do esforço de pesquisa sobre as despesas de I\&D. A evidência empírica disponível aponta no sentido de que tais despesas tendem a ser valorizadas positivamente pelos investidores, i.e. têm relevância informativa para efeitos da avaliação das empresas (e.g. Hirshey, 1982). Tendo em consideração que no contexto institucional a que esses estudos se reportam tais despesas são contabilizadas integralmente como gastos do exercício, tal relevância significa que as mesmas são consideradas pelos investidores como autênticos activos intangíveis. É como se, a partir das despesas de I\&D levadas a gastos, se constituísse um stock acumulado implícito de «capital de desenvolvimento", correspondente grosso modo à parte dessas despesas que ainda terá condições para contribuir para a geração de resultados futuros (e.g. Lev e Sougiannis, 1999; Sougiannis et al., 2001; Green et al., 1996, para o contexto inglês).

A investigação também tem mostrado que os investidores, a partir da mera divulgação dos gastos com I\&D e, muitas vezes, sem outra informação adicional que ajude a perceber o que está subjacente a tais números, sentem dificuldade em fazer uma correcta formulação de expectativas sobre os benefícios económicos futuros desses gastos resultantes para o valor da empresa. Daí uma maior volatilidade do preço das acções das empresas intensivas em I\&D (e.g. Sougiannis et al., 2001) ou mesmo a sobrevalorização do preço das acções das empresas intensivas em I\&D (Nascimento, 2007, para o contexto inglês).

Esta dificuldade dos investidores em estimarem o impacto da I\&D tende a ocorrer mesmo quando eles se socorrem de informação complementar. Por exemplo, Chiang e Mensah (2004), estudando o sector do software, encontram evidência que aponta no sentido de que 
determinantes como o aumento de produtividade da empresa, a proporção de trabalhadores com elevada formação, a quota de mercado da empresa, a diversidade de produtos e o ciclo de vida dos mesmos, são consideradas na formulação de expectativas sobre o impacto das despesas de I\&D. Em idêntico sentido, Liu (2006), que estuda o sector da biotecnologia.

Em relação ao caso português, conhecem-se dois trabalhos que, em parte, se debruçam sobre aspectos relacionados com a relevância informativa das despesas de I\&D. O primeiro, realizado por Fonseca (2001), para o período 1995-2000 e as empresas cotadas na Euronext Lisbon, avalia a relevância dos activos intangíveis constantes do balanço, de forma agregada, não autonomizando a parte respeitante a I\&D, muito menos a parte desta rubricas levada directamente a gastos do período. A evidência sugere a existência de uma relação positiva entre tais activos e o valor das empresas, como era de esperar. O segundo estudo, Leote (2006), que se debruça sobre a mesma amostra, mas para o período 1997-2001, testa a relevância informativa das despesas de I\&D, mas considera apenas as que são capitalizadas no período. Neste aspecto, nomeadamente, distingue-se do presente estudo, que tem uma maior abrangência e testa, também, a relevância do stock de I\&D acumulado no balanço e a informação de natureza qualitativa. Não encontra evidência empírica que corrobore essa relevância. Esse resultado, algo inesperado, pode ter a ver com o modo como o estudo é conduzido, ao considerar o valor de mercado da empresa referido ao final do ano, ainda antes da informação sobre a empresa e relativa a um determinado exercício estar completamente reflectida nas cotações; mas pode ser, também, resultante do facto de os investidores não anteciparem que os montantes de I\&D capitalizados em cada período possam vir a ter impacto significativo nos resultados e cash flows futuros. O estudo é omisso na discussão de uma justificação para o resultado obtido.

Em suma, do que se referiu na presente secção a propósito da relevância das despesas de I\&D, ressalta o facto dos investidores tenderem a atribuir valor a tais despesas, embora contabilisticamente elas possam ser consideradas como um gasto do exercício. As características das empresas e ou do sector em que se inserem parecem ser tidas em consideração pelos investidores nessa avaliação. Sobre este último aspecto, tecem-se considerações adicionais na secção seguinte.

\subsection{Importância da informação não financeira na relevância informativa da I\&D}

Um segundo ramo de investigação nesta área agrega estudos que conjugam informação não financeira sobre a I\&D - como por exemplo as patentes - com informação financeira (e.g. Hirschey et al., 2001; Deng et al., 1999; Chiang e Mensah, 2004). Destacam a necessidade desta complementaridade sobretudo em indústrias mais concorrenciais e, muito particularmente, em países como os EUA onde o normativo contabilístico não permite a capitalização de qualquer parcela das despesas de I\&D.

Estudos como os de Brown et al. (1999) e Francis e Schipper (1999) sugerem a perda de relevância informativa das demonstrações financeiras nas últimas décadas. Uma das causas potenciais apontadas é a falta de informação de natureza não financeira que permita melhorar a apreensão do conteúdo informativo das despesas de I\&D. Principalmente em sectores caracterizados por rápidas mudanças, onde a I\&D é fundamental, a informação financeira sobre tais despesas nem sempre é suficiente, relevante e disponibilizada atempadamente para uma correcta avaliação pelos investidores. Neste contexto, os trabalhos de Hirschey et al. (2001) e de Deng et al. (1999) são exemplos da importância que pode assumir a informação sobre patentes na antecipação do impacto das despesas de I\&D na rendibilidade futura das empresas. O mérito científico das patentes melhora a avaliação que o investidor faz dessas despesas.

Em suma, há evidência empírica de que as citações relativas à capacidade científica e ao número de patentes como output do processo de inovação são informações complementares usadas pelos investidores na avaliação da relevância informativa das despesas I\&D.

Em Portugal, embora não exista pesquisa académica sobre o assunto, as características da I\&D efectuada e também o fraco volume em cada ano investido sugerem que as patentes registadas 
são escassas e, por isso, parecem não ser um elemento preponderante para os investidores no processo de antecipação do impacto desse tipo de investimento.

\subsection{Relevância informativa do tratamento contabilístico das despesas de I\&D}

O normativo do IASB (IAS 38), de utilização obrigatória a partir de 2005 para um conjunto de empresas cotadas em bolsa e que apresentem contas consolidadas, e que é extensível, por via do SNC, às restantes empresas portuguesas a partir de 2010, impõe que as despesas com investigação sejam contabilizadas como gastos do exercício. Permite, no entanto, que as despesas de desenvolvimento, demonstrado que seja que poderão ocasionar benefícios económicos futuros, possam ser contabilizadas como activos intangíveis e figurar no balanço. Em contraponto, o normativo do FASB - Financial Accounting Standard Board, que é seguido pelas empresas americanas, impõe que todas as despesas, independentemente de serem de investigação ou de desenvolvimento, sejam contabilizadas como gastos do exercício.

Há um ramo de investigação nesta área que estuda se o tratamento contabilístico das despesas de I\&D contribui diferentemente para a avaliação das empresas. Este tipo de investigação parte do pressuposto de que as despesas capitalizadas tenderão a estar associadas a uma mais elevada expectativa de um retorno positivo do que as que são levadas a gastos e, por esse motivo, terão maior relevância informativa (e.g. Aboody e Lev, 1998; Callimaci e Landry, 2004; Oswald e Zarowin, 2007). A evidência empírica tende a apoiar tal pressuposto, sugerindo que as despesas capitalizadas tendem a possuir maior relevância informativa do que as que são levadas a gastos. A justificação para tal parece assentar no facto de as despesas capitalizadas terem subjacente a distinção entre projectos viáveis e economicamente rentáveis, de projectos ainda numa fase muito embrionária ou sem expectativas bem formadas sobre a respectiva rendibilidade futura.

Esta evidência afigura-se de particular importância para o presente estudo, pois permite formular uma expectativa dos resultados a esperar. Com efeito, o estudo testará a relevância informativa das despesas de I\&D capitalizadas, mas também a da informação de natureza qualitativa disponibilizada nos relatórios e contas.

Uma variante deste tipo de estudos procura avaliar o impacto de alterações normativas que afectem o modo de contabilização das despesas de I\&D (e.g. Selto e Clouse,1985 e Amir et al., 2007, ambos para a realidade norte-americana). Estes dois estudos, na sequência da evidência conhecida quanto ao impacto do modo de contabilização, sugerem que as alterações nesse modo impostas por modificações no quadro normativo podem ter influência nas escolhas contabilísticas dos gestores e no valor da empresa. Ou seja, mesmo sem colocarem em causa a eficiência do mercado, este tipo de estudos parece sugerir que a forma como a informação é divulgada interfere na avaliação da empresa, i.e. tem impacto económico.

Para o caso português, não se conhece literatura que estude o impacto na avaliação das despesas de I\&D resultantes de alterações normativas. O presente estudo será o primeiro a abarcar um período que compreende em si uma alteração normativa de monta (o ano de 2005). Já quanto ao tratamento contabilístico da I\&D, há um conjunto de três referências que se impõe mencionar. Comum às três, a conclusão de que a informação divulgada é escassa e tende a ser de fraca qualidade. Ferreira et al. (2001), concluiu, adicionalmente, que a informação disponível sobre I\&D é determinada essencialmente pelas regras fiscais; Leitão (2006), sugere que não é significativa a existência de divulgação de natureza voluntária; Silva (2007), estudando o caso de empresas com projectos de I\&D financiados ao abrigo de programas de incentivo ao investimento, conclui que as empresas tendem, em tais casos, a capitalizar as despesas de I\&D.

\subsection{Uma súmula}

No presente capítulo procurou fornecer-se uma perspectiva genérica de diferentes linhas de investigação que têm em comum o teste da relevância informativa das despesas de I\&D. A literatura tende a ser genericamente consensual quanto à valorização positiva dessas despesas 
pelos investidores, bem como à utilização por estes de informação não financeira para ajudar na formulação de estimativas quanto ao impacto da I\&D nos resultados futuros. Não é tão assertiva, no entanto, quanto à influência que o modo de contabilização das despesas de I\&D tem na avaliação das empresas, embora a evidência empírica sugira que a relevância informativa é diferente consoante o modo de contabilização e divulgação.

\section{Estudo empírico}

Neste capítulo analisa-se empiricamente a relevância informativa das despesas de I\&D para uma amostra de empresas não financeiras cotadas na Euronext Lisbon e obrigadas à observância do normativo do IASB (IAS 38).

A adopção das NIC a partir de 2005 não veio alterar significativamente o enquadramento subjacente à contabilização das despesas de I\&D - veja-se o disposto na Directriz Contabilística n. ${ }^{\circ} 7 / 92$. Essencialmente, o que mudou foi o grau de enforcement, que aumentou, tornando mais difícil a capitalização dessas despesas. Daí resultou, como seria de esperar, uma redução substancial do número de empresas a capitalizar despesas de I\&D a partir desse ano.

Relativamente aos estudos de matriz anglo-saxónica acima referidos, o presente padece de uma importante limitação de índole operacional: são muito poucas as empresas que divulgam informação quantitativa sobre as despesas de I\&D contabilizadas como gasto em cada período. Para a generalidade delas, a informação disponível sobre a I\&D é de ordem qualitativa ou respeita ao montante capitalizado disponível no balanço.

Tendo presente esta limitação, na secção seguinte formulam-se as hipóteses de investigação que serão testadas.

\subsection{Formulação das hipóteses de investigação}

Tal como nos estudos de Oswald e Zarowin (2007), Cockburn e Griliches (1988), Sougiannis (1994) e Chiang e Mensah (2004), o objectivo do presente estudo é averiguar a relevância informativa das despesas de I\&D. A evidência empírica disponível na literatura sugere que essa relevância existe, i.e. que essas despesas influenciam de forma positiva e consistente o valor de mercado das empresas.

Neste contexto, formula-se a seguinte hipótese de investigação:

H1: Os investidores valorizam positivamente a informação sobre despesas de I\&D disponibilizada pelas empresas não financeiras cotadas na Euronext Lisbon.

Aboody e Lev (1998) e Oswald e Zarowin (2007) apresentam evidência empírica de que a informação sobre a I\&D capitalizada é avaliada pelos investidores diferentemente da outra informação sobre despesas de I\&D, nomeadamente da informação levada a gastos do exercício. Essa evidência sugere que a I\&D capitalizada é associada de forma acrescida ao valor da empresa.

No presente estudo não se testará tal possibilidade dada a falta de informação sobre o montante da I\&D levada directamente a gastos. No entanto, as empresas portuguesas disponibilizam nos seus relatórios e contas referências de ordem genérica e não quantificada relativas a despesas de I\&D levadas a cabo durante o período. Tendo presente a evidência empírica disponível em estudos como os referidos, a expectativa é a de que este último tipo de informação não apresente valor incremental relativamente à informação sobre despesas de I\&D capitalizadas.

Neste contexto, formula-se a seguinte hipótese de investigação:

H2: Informações não quantificadas sobre despesas de I\&D, disponibilizadas de forma genérica no relatório e contas das empresas, são olhadas pelos investidores como isentas de valor incremental relativamente à informação disponibilizada no balanço e relativa à capitalização de I\&D.

Na secção seguinte apresentam-se os modelos estatísticos usados para testar as hipóteses empíricas agora formuladas. 


\subsection{Modelos econométricos}

A literatura da especialidade fornece uma ampla panóplia de modelos para testar a value relevance das despesas de I\&D.

Para Ohlson (1995), o valor de mercado da empresa está relacionado com a informação contabilística contemporânea constante dos relatórios financeiros, nomeadamente o montante dos capitais próprios e o resultado líquido do exercício, bem como "outra informação" ainda não reflectida nos números financeiros mas já reflectida no valor de mercado. Os modelos que serão utilizados para testar as hipóteses acima definidas são construídos a partir do modelo proposto por este autor, em que as variáveis da I\&D podem ser olhadas como «proxies» da referida "outra informação". Com as devidas adaptações, tendo em consideração o foco do estudo, idênticas soluções foram adoptadas por Core et al. (2003) e Green et al. (1996). Para ter em consideração a evidência recolhida por Hayn (1995), quanto à diferente relevância valorativa dos lucros comparativamente às perdas, os modelos utilizados controlam para tal efeito através da inserção de duas variáveis $\left(D D\right.$ e $\left.D D^{*} R L / C P\right)$ a seguir definidas ${ }^{2}$.

\section{Modelo1:}

$\frac{V M 3_{t}}{C P_{t}}=\delta_{0}+\delta_{1} \frac{R L_{t}}{C P_{t}}+\delta_{2} D D_{t}+\delta_{3} D D_{t} \frac{R L_{t}}{C P_{t}}+\delta_{4} \frac{S I \& D_{t}\left(I \& D_{t}\right)}{C P_{t}}+\sum \delta_{j} I N D_{i}+\sum \delta_{l} A N O+\varepsilon$

Modelo 2:

$\frac{V M 3_{t}}{C P_{t}}=\delta_{0}+\delta_{1} \frac{R L_{t}}{C P_{t}}+\delta_{2} D D_{t}+\delta_{3} D D_{t} \frac{R L_{t}}{C P_{t}}+\delta_{4} R E F_{-} I \& D_{t}+\sum \delta_{j} I N D_{i}+\sum \delta_{l} A N O+\varepsilon$

Modelo 3:

$$
\begin{aligned}
\frac{V M 3_{t}}{C P_{t}} & =\delta_{0}+\delta_{1} \frac{R L_{t}}{C P_{t}}+\delta_{2} D D_{t}+\delta_{3} D D_{t} \frac{R L_{t}}{C P_{t}}+\delta_{4} \frac{S I \& D_{t}\left(I \& D_{t}\right)}{C P_{t}}+\delta_{5} R E F_{-} I \& D_{t}+ \\
& +\sum \delta_{j} I N D_{i}+\sum \delta_{l} A N O+\varepsilon
\end{aligned}
$$

onde:

$V M 3_{t}=$ Valor de mercado da empresa no final do mês de Março do ano $t+1^{3}$;

$R L_{t}=$ Resultado líquido da empresa no ano $t$;

$D D_{t}=$ Variável dummy que assume o valor 1 quando a variável $R L_{t}$ é negativa, 0 no caso oposto;

$C P_{t}=$ Capital próprio da empresa no ano $t$;

$R E F \_I \& D_{t}=$ Variável dummy que assume o valor 1 quando empresa refere actividades de I\&D no seu relatório e contas do ano $t$ mas não capitaliza qualquer montante dessas despesas, 0 no caso oposto;

$S / \& D_{t}=$ Valor líquido do stock de I\&D divulgado no Balanço da empresa no ano $t$;

$1 \& D_{t}=$ Montante de I\&D capitalizado no ano $t$, aferido a partir da variação do stock de $I \& D$ constante do Balanço ${ }^{4}$;

2 Para o caso português, pode encontrar-se este tipo de controlo em Trabucho (2007). Na amostra seleccionada para o presente estudo, cerca de $25 \%$ das observações apresentam resultados do período negativos.

3 Tal como em Core et al. (2003), o valor de mercado é considerado com data posterior à do encerramento do exercício, de modo a poder reflectir toda a informação contabilística a ele referente. No entanto, os testes foram replicados considerando aquele valor à data de 31 de Dezembro do ano $t$, sem que se tenham detectado diferenças qualitativas significativas relativamente aos resultados tabelados.

4 Testou-se, alternativamente, a relevância do stock de capital $(S / \& D / C P)$ e o montante capitalizado no período $(I \& D / C P)$. 
$A N O$ = conjunto de variáveis dummy que controlam para o ano da observação;

IND = conjunto de variáveis dummy que controlam para a indústria da empresa;

$\varepsilon=$ Termo de perturbação aleatório.

As variáveis ANO e IND controlam, respectivamente, para os factores tempo e indústria. As diferenças entre as três versões apresentadas para o modelo residem na natureza da(s) variável(eis) utilizada(s) para reflectir a informação relativa às despesas de I\&D.

Os modelos 1 e 2 testam a hipótese $H 1$. Independentemente da forma de contabilização das despesas de I\&D e do modo de divulgação da informação, procura saber-se se o mercado valoriza positivamente estas despesas. O modelo 3 testa o valor incremental de REF_I\&D relativamente a SI\&D (ou I\&D), isto é, testa $H 2$. Os modelos são estimados pelo método dos mínimos quadrados para um painel não balanceado de dados (estimação em painel com efeitos fixos por ano e indústria) $)^{5}$.

\section{Definição das variáveis}

A variável dependente é o valor de mercado (VM3), correspondendo ao produto do número de acções da empresa e a cotação no final de Março do ano $t+1$, de modo a reflectir toda a informação relativa ao exercício findo (e.g. Core et al., 2003; Sougiannis, 1994). Como teste de robustez dos resultados, estimar-se-ão também os modelos com o valor de mercado referido ao final do exercício. As cotações foram recolhidas da base de dados DATHIS para os anos 2000 a 2006. O número de acções foi recolhido do relatório e contas anual de cada empresa.

As variáveis explicativas contabilísticas são relativas às contas consolidadas.

Os resultados líquidos $(R L)$ foram coligidos a partir da base de dados $S A B I$. Nos casos em que essa informação não estava disponível recorreu-se aos relatórios e contas anuais respectivos. Espera-se que esta variável tenha um impacto positivo no valor de mercado da empresa (e.g. Core et al., 2003), uma vez que é um dos principais indicadores da criação de valor presente e da capacidade de criação futura.

Os capitais próprios $(C P)$ foram coligidos de modo semelhante ao $R L$. A variável CP é utilizada para deflacionar as variáveis quantitativas e tem em vista eliminar eventuais efeitos de heterocedasticidade na estimação do modelo, contribuindo para obter coeficientes centrados e eficientes. Por outro lado, a utilização desta variável como deflator apresenta a vantagem de transformar a variável dependente no rácio entre o valor de mercado e o valor contabilístico da empresa, identificado na literatura com uma das medidas da relevância dos activos intangíveis não reflectidos contabilisticamente nas variáveis contabilísticas (e.g. Core et al., 2003).

A variável dummy relativa às despesas de investigação e desenvolvimento (REF_\&D) foi definida com base na informação que as empresas divulgam no seu relatório e contas, e foi coligida manualmente. Se a empresa refere actividades de I\&D no relatório de gestão ou se apresenta os critérios valorimétricos com que regista estas despesas ou ainda se apresenta os montantes dispendidos, mas, em caso algum, capitaliza despesas de I\&D no período, esta variável assume o valor 1; assume o valor 0 em caso contrário.

A variável stock de investigação e desenvolvimento (SI\&D) corresponde ao valor das despesas de I\&D capitalizadas no balanço, líquido de amortizações, e foi recolhida a partir da base de dados $S A B I$. Alternativamente, com idêntico propósito, também foi usada a variável I\&D, que respeita ao montante da capitalização deste tipo de despesas no exercício.

As variáveis $\Sigma A N O$ são um conjunto de variáveis dummy que assumem o valor 1 quando as observações correspondem ao ano $t, 0$ nos outros casos, $t=2000 \ldots$ 2006. De modo 
semelhante, as variáveis $\sum$ IND são um conjunto de variáveis dummy que assumem o valor 1 quando as empresas pertencem à indústria $S$ e 0 nos outros casos, em que $S=1,2, \ldots 9$ corresponde à classe da $C A E$ - Classificação das Actividades Económicas.

\subsection{Amostra e estatísticas descritivas}

Este estudo tem por base um conjunto de quarenta e sete empresas (grupos) cotadas na bolsa de valores portuguesa (Euronext Lisbon), no período 2000-2006, a que correspondem 240 observações. O quadro seguinte apresenta a amostra seleccionada.

\begin{tabular}{l|c}
\hline Quadro 1 - Selecção da amostra & \multicolumn{1}{c|}{ Descrição } \\
\hline \multicolumn{1}{c}{ N.0 Empresas-ano } \\
$\begin{array}{l}\text { Informação contabilística recolhida na base de dados SABI (2006) e } \\
\text { cotações recolhidas da base de dados Dathis. Observações (empresas- }\end{array}$ \\
$\begin{array}{l}\text {-ano) relativas a sociedades anónimas cotadas na Euronext Lisbon no } \\
\text { período 2000-2006 }\end{array}$ \\
\hline Amostra após eliminação de empresas-ano cujo capital próprio é negativo \\
\hline Amostra de trabalho depois de eliminados os outliers & 246 \\
\hline Empresas-ano no período 2000-2004 & 235 \\
\hline Empresas-ano no período 2005-2006 & 156 \\
\hline
\end{tabular}

A identificação de outliers foi feita através da análise dos resíduos estandardizados, sendo eliminados os que apresentavam um valor superior a 3. A separação da amostra em dois subperíodos prende-se com o objectivo de avaliar se a obrigatoriedade de apresentar as contas a partir de 2005 de acordo com as NIC teve impacto na relevância da informação relativa à I\&D. O Quadro 2 apresenta estatísticas descritivas para as principais variáveis dos modelos.

\begin{tabular}{|c|c|c|c|}
\hline Variável & Média & DP & Mediana \\
\hline VM3/CP & 2,182 & 1,897 & 1,634 \\
\hline $\mathrm{RL} / \mathrm{CP}$ & $-0,017$ & 0,550 & 0,072 \\
\hline $\mathrm{DD}$ & 0,243 & 0,429 & 0,000 \\
\hline $\mathrm{DD} * \mathrm{RL} / \mathrm{CP}$ & $-0,136$ & 0,502 & 0,000 \\
\hline SI\&D/CP & 0,053 & 0,365 & 0,002 \\
\hline SI\&D/CP (2000-2004) & 0,058 & 0,416 & 0,005 \\
\hline SI\&D/CP (2005-2006) & 0,039 & 0,232 & 0,000 \\
\hline I\&D/CP & 0,022 & 0,201 & 0,000 \\
\hline I\&D/CP (2000-2004) & 0,026 & 0,237 & 0,000 \\
\hline I\&D/CP (2005-2006) & 0,015 & 0,101 & 0,000 \\
\hline REF_I\&D & 0,187 & 0,390 & 0,000 \\
\hline
\end{tabular}

Definição das variáveis: «VM3/CP» é o valor de mercado em 31 de Março de $t+1$, deflacionado pelo capital próprio; «RL/CP» é o resultado líquido do período, deflacionado pelo capital próprio; « $D D$ » é uma variável dummy que assume o valor 1 se os resultados líquidos do período forem negativos, 0 no caso contrário; « $D D^{*} R L / C P$ » é uma variável interactiva, definida pelo produto entre as duas variáveis imediatamente anteriores; «SI\&D/CP» é o stock líquido de I\&D, deflacionado pelo capital próprio; «I\&D/CP» é o montante de despesas de I\&D capitalizadas no período, deflacionado pelo capital próprio; «REF_I\&D» é uma variável dummy que assume o valor 1 se a empresa faz referência à I\&D no seu relatório e contas, mas não capitaliza tais despesas no período, 0 no caso oposto. À excepção do valor de mercado, todas as variáveis reportam à data de 31 de Dezembro. 
Os valores apresentados no quadro mostram, como era de esperar, que o valor de mercado do capital próprio é superior ao respectivo valor contabilístico, quer se olhe à média ou à mediana da variável. Este rácio reflecte a existência de informação não contabilisticamente relevada e que contribui para o valor de mercado das empresas. É consistente, portanto, nomeadamente, com a existência de despesas de I\&D que irão produzir efeitos sobre os resultados futuros.

A variável $R L / C P$ apresenta média negativa, contrariando o que seriam as expectativas em relação a empresas de grande dimensão cotadas na Euronext Lisbon. A conjuntura económica menos propícia vivida no período poderá ajudar a explicar tal situação. No entanto, na identificação das 60 observações que contribuem para o valor negativo desta estatística observa-se o contributo reiterado de um conjunto de empresas com resultados negativos em vários anos. A média desta variável por anos permitiu verificar que ela só foi positiva em 2000 , 2004 e 2005.

A média da variável $S / \& D / C P$ sofre de influência significativa de um conjunto de empresas que apresentam valores elevados de despesas capitalizadas. Das 69 observações nulas desta variável destaca-se que 52 pertencem aos anos de 2005 e 2006, em que menos empresas apresentaram despesas de I\&D capitalizadas, em virtude do enforcement para a observância da IAS 38. É visível, a partir da informação tabelada, que a adopção das NIC em 2005 teve repercussões no modo como as empresas passaram a contabilizar as despesas de I\&D. A capitalização anual $(I \& D / C P)$ em média passou a ser menor, relativamente ao período anterior, reflectindo-se igualmente no stock capitalizado $(S / \& D / C P)$.

Em relação à variável dummy REF_I\&D, mas não visível na tabela, será de referir a menor frequência de referências por parte das empresas a este tipo de despesas nos anos de $2005 \mathrm{e}$ 2006, porventura devido à adopção do normativo internacional e à imposição de divulgação de mais informação obrigatória no anexo às contas.

Uma análise das correlações entre estas variáveis (não tabelada) permite verificar que elas são, em geral, reduzidas, embora significativas dentro dos padrões habituais. Daí que, para a estimação dos modelos, não se afigure passível de ocorrerem problemas de multicolinearidade.

\subsection{Resultados empíricos da estimação dos modelos}

\subsubsection{Período 2000-2006}

No Quadro 3 apresentam-se os resultados da estimação dos três modelos para o período global do estudo, abstraindo para já de que em 2005 as empresas da amostra tiveram que adoptar um novo normativo contabilístico.

Os resultados do modelo 1 apresentados no Quadro 3 corroboram a expectativa que se havia formulado inicialmente em relação à avaliação pelo mercado do stock de despesas de I\&D capitalizadas $(S / \& D / C P)$. O coeficiente associado a esta variável é positivo e estatisticamente significativo, sugerindo que os investidores consideram que as despesas com I\&D capitalizadas contribuem positivamente para gerar valor. O mesmo acontece quando se utiliza a variável I\&D/CP (não tabelada), relativa ao montante capitalizado em cada período.

Por outro lado, a regressão do modelo 2 reflecte, através do coeficiente da variável $R E F \_I \& D$, a importância tributada pelo mercado à divulgação de informação sobre as actividades de I\&D quando as empresas não capitalizam as correspondentes despesas. A respectiva significância, dentro dos níveis habituais, sugere que os investidores consideram a I\&D como uma actividade de criação de valor, mesmo nos casos em que a empresa pouco mais divulga do que uma menção à existência de tal tipo de actividade. Embora o nível de significância da variável $R E F \_I \& D$ seja menor do que o da sua congénere no modelo 1 , constata-se que o poder explicativo dos dois modelos, traduzido nos $R^{2}$ ajustados, é muito semelhante. A mais elevada significância da variável $S I \& D$ poderá ser explicada, potencialmente, pelo maior rigor e fiabilidade da informação que está subjacente a esta variável, relativamente a REF_I\&D. Com efeito, só 


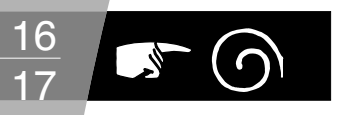

Quadro 3 - Relevância informativa da I\&D no período 2000-2006

\begin{tabular}{|c|c|c|c|c|}
\hline $\begin{array}{c}\text { Variáveis } \\
\text { Independentes }\end{array}$ & $\begin{array}{c}\text { Sinal } \\
\text { esperado }\end{array}$ & $\begin{array}{c}\text { Modelo } 1 \\
\text { Coefic. (p-value) }\end{array}$ & $\begin{array}{c}\text { Modelo } 2 \\
\text { Coefic. (p-value) }\end{array}$ & $\begin{array}{c}\text { Modelo } 3 \\
\text { Coefic. (p-value) }\end{array}$ \\
\hline CONSTANTE & $?$ & $\begin{array}{r}0,028 \\
(0,966)\end{array}$ & $\begin{array}{r}0,092 \\
(0,883)\end{array}$ & $\begin{array}{r}0,038 \\
(0,953)\end{array}$ \\
\hline$R L / C P$ & + & $\begin{array}{r}5,789 \\
(0,000)\end{array}$ & $\begin{array}{r}5,931 \\
(0,000)\end{array}$ & $\begin{array}{r}5,647 \\
(0,000)\end{array}$ \\
\hline$D D$ & $?$ & $\begin{array}{l}-0,039 \\
(0,896)\end{array}$ & $\begin{array}{l}-0,036 \\
(0,898)\end{array}$ & $\begin{array}{l}-0,059 \\
(0,844)\end{array}$ \\
\hline$D D^{*} R L / C P$ & - & $\begin{array}{l}-6,293 \\
(0,000)\end{array}$ & $\begin{array}{l}-6,717 \\
(0,000)\end{array}$ & $\begin{array}{l}-6,153 \\
(0,000)\end{array}$ \\
\hline$S I \& D / C P$ & + & $\begin{array}{r}1,172 \\
(0,000)\end{array}$ & & $\begin{array}{r}1,191 \\
(0,000)\end{array}$ \\
\hline$R E F \_I \& D$ & + & & $\begin{array}{r}0,528 \\
(0,071)\end{array}$ & $\begin{array}{r}0,441 \\
(0,150)\end{array}$ \\
\hline \multicolumn{5}{|l|}{$\ldots$} \\
\hline $\begin{array}{l}R^{2} \\
R^{2} \text { ajustado } \\
\text { Teste } F \text { ( } p \text {-value })\end{array}$ & & $\begin{array}{l}0,416 \\
0,370 \\
0,000\end{array}$ & $\begin{array}{l}0,409 \\
0,363 \\
0,000\end{array}$ & $\begin{array}{l}0,422 \\
0,374 \\
0,000\end{array}$ \\
\hline
\end{tabular}

Notas: i) Controlou-se para os efeitos fixos de ano e indústria. Por questões de parcimónia, não se tabelam os respectivos coeficientes. Porém, eles são quase sempre não significativos; ii) a definição das variáveis é feita no Quadro 2; iii) a amostra contém 235 observações.

podem ser capitalizadas as despesas de I\&D para as quais se demonstre que os resultados económicos futuros esperados com esta actividade serão superiores aos investimentos iniciais. Parece plausível, pois, que o conteúdo informativo da variável I\&D do modelo 1 seja superior à do modelo 2 .

Os resultados da regressão dos modelos 1 e 2 permitem validar a hipótese 1 (H1), ou seja, o mercado valoriza positivamente as despesas de $I \& D$, mesmo quando estas não são capitalizadas, mas de modo particular quando o são.

A evidência empírica resultante da estimação do modelo 3 confirma os resultados do modelo 1 , uma vez que o coeficiente associado à variável $S / \& D$ é positivo e estatisticamente significativo. No entanto, a variável dummy REF_I\&D apesar de manter o sinal positivo deixou de ser, para os níveis habituais de significância, estatisticamente significativa, o que parece indicar, como atrás se referiu, que o mercado reconhece mais valor à informação sobre despesas capitalizadas, por ser mais informativa quanto ao futuro da empresa. Relativamente à informação generalista sobre a realização de actividades de I\&D (REF_I\&D), o seu valor incremental é nulo relativamente a SI\&D/CP, confirmando a hipótese $H 2$. Trata-se de um resultado que, além do mais, é intuitivo quanto à importância relativa dada pelos investidores a informação quantificada e certificada por contraponto a informação de carácter genérico. De um modo geral, esta evidência é consistente com a disponível na literatura, exceptuando para o caso português Leote (2006), em que a relevância do montante de I\&D capitalizado no exercício é não significativa no período 1997-2001.

Os coeficientes das variáveis de controlo associadas ao resultado líquido apresentam os sinais esperados. A variável $D D^{*} R L / C P$ apresenta um coeficiente negativo que se explica pelo sinal dos resultados líquidos que lhe estão associados, significando que o valor incremental deste tipo de resultados para o valor da empresa é negativo. Ao contrário, os resultados líquidos positivos são olhados pelos investidores como um contributo positivo para o valor de mercado da empresa. Também neste caso, a evidência é consistente com a conhecida de outros estudos. 


\subsubsection{Períodos pré- e pós-adopção do normativo do IASB em 2005}

Considerando que 2005 foi o ano em que as empresas tiveram que apresentar as suas demonstrações financeiras de acordo com o normativo do IASB (NIC) e que a adopção deste implicou, como se viu pelas estatísticas descritivas, impacto na contabilização das despesas de I\&D, testa-se agora se o novo normativo contabilístico implicou alterações no valor informativo dessas despesas.

Assim, no Quadro 4 apresentam-se os resultados da regressão do modelo 3 para os períodos prée pós-2005, nas variantes stock de I\&D (S/\&D/CP) e capitalização de I\&D no exercício $(I \& D / C P)^{6}$.

\begin{tabular}{|c|c|c|c|c|c|}
\hline \multicolumn{3}{|c|}{ Quadro 4 - Relevância informativa da I\&D nos períodos pré- e pós-2005 } & & & \\
\hline \multirow{3}{*}{$\begin{array}{c}\text { Variáveis } \\
\text { Independentes }\end{array}$} & \multirow{3}{*}{$\begin{array}{c}\text { Sinal } \\
\text { esperado }\end{array}$} & \multirow{2}{*}{\multicolumn{2}{|c|}{\begin{tabular}{|c|}
$2000-2004$ \\
Modelo 3 \\
\end{tabular}}} & & \\
\hline & & & & \multicolumn{2}{|c|}{ Modelo 3} \\
\hline & & $\begin{array}{l}\text { Stock 18Dt } \\
\text { Coefic. } \\
\text { (p-value) }\end{array}$ & $\begin{array}{l}\text { 18D capitaliz.t } \\
\text { Coefic. } \\
\text { (p-value) }\end{array}$ & $\begin{array}{l}\text { Stock I\&Dt } \\
\text { Coefic. } \\
\text { (p-value) }\end{array}$ & $\begin{array}{l}\text { I8D capitaliz.t } \\
\text { Coefic. } \\
\text { (p-value) }\end{array}$ \\
\hline CONSTANTE & $?$ & $\begin{array}{r}0,545 \\
(0,335) \\
\end{array}$ & $\begin{array}{r}0,542 \\
(0,339) \\
\end{array}$ & $\begin{array}{r}0,986 \\
(0,233) \\
\end{array}$ & $\begin{array}{r}0,778 \\
(0,328) \\
\end{array}$ \\
\hline$R L / C P$ & + & $\begin{array}{r}7,005 \\
(0,000)\end{array}$ & $\begin{array}{r}7,027 \\
(0,000) \\
\end{array}$ & $\begin{array}{r}2,974 \\
(0,033)\end{array}$ & $\begin{array}{r}4,459 \\
(0,001) \\
\end{array}$ \\
\hline$D D$ & $?$ & $\begin{array}{r}0,206 \\
(0,493)\end{array}$ & $\begin{array}{r}0,216 \\
(0,474)\end{array}$ & $\begin{array}{l}-0,836 \\
(0,203)\end{array}$ & $\begin{array}{l}-0,628 \\
(0,321)\end{array}$ \\
\hline$D D^{*} R L / C P$ & - & $\begin{array}{l}-7,601 \\
(0,000)\end{array}$ & $\begin{array}{l}-7,597 \\
(0,000)\end{array}$ & $\begin{array}{l}-3,948 \\
(0,006)\end{array}$ & $\begin{array}{l}-5,426 \\
(0,000) \\
\end{array}$ \\
\hline$S / \& D / C P$ & + & $\begin{array}{r}0,790 \\
(0,005)\end{array}$ & & $\begin{array}{r}4,340 \\
(0,000)\end{array}$ & \\
\hline I\&D/CP & + & & $\begin{array}{r}1,343 \\
(0,008)\end{array}$ & & $\begin{array}{l}10,411 \\
(0,000)\end{array}$ \\
\hline$R E F \_I \& D$ & + & $\begin{array}{r}2,564 \\
(0,000)\end{array}$ & $\begin{array}{r}2,556 \\
(0,000)\end{array}$ & $\begin{array}{r}0,115 \\
(0,765)\end{array}$ & $\begin{array}{r}0,037 \\
(0,920)\end{array}$ \\
\hline$\ldots$ & & & & & \\
\hline $\begin{array}{l}R^{2} \\
R^{2} \text { ajustado } \\
\text { Teste } F \text { ( } p \text {-value) } \\
N\end{array}$ & & $\begin{array}{r}0,503 \\
0,461 \\
0,000 \\
156 \\
\end{array}$ & $\begin{array}{r}0,500 \\
0,458 \\
0,000 \\
156\end{array}$ & $\begin{array}{r}0,502 \\
0,412 \\
0,000 \\
79 \\
\end{array}$ & $\begin{array}{r}0,537 \\
0,452 \\
0,000 \\
79 \\
\end{array}$ \\
\hline
\end{tabular}

Notas: i) Controlou-se para os efeitos fixos de indústria. Por questões de parcimónia, não se tabelam os respectivos coeficientes. Porém, eles são quase sempre não significativos; ii) “Stock I\&Dt» é o montante líquido de I\&D capitalizado existente no balanço em final do exercício; «/\&D capitaliz.t» é o montante de I\&D capitalizado no período. A definição das restantes variáveis é feita no Quadro 2; iii) a amostra contém 235 observações.

Constata-se, a partir da informação tabelada, que os coeficientes das variáveis $S / \& D / C P$ e I\&D/CP são significativos em ambos os subperíodos, situação que tende a corroborar a evidência média discutida no Quadro 3 e colide com a evidência empírica em Leote (2006). Porém, o nível de significância desses coeficientes, medido pelas respectivas estatísticas $t$ de Student, aumentou no subperíodo 2005-2006. Esta constatação é consistente com o facto de que, usando o valor de mercado à data de 31 de Dezembro, alternativamente à solução tabelada que se refere a 31 de Março, os coeficientes dessas variáveis no subperíodo 2000-2004 não serem significativos (valores não tabelados). Ou seja, o rigor na aplicação das NIC no que 
respeita à capitalização de despesas de I\&D parece ter aumentado a credibilidade da informação de natureza quantitativa ${ }^{7}$.

Já quanto à informação de natureza qualitativa, subjacente à variável $R E F \_I \& D$, ela é relevante no primeiro subperíodo (2000-2004), mas perde essa qualidade no segundo, quer no modelo 2 (não tabelado), quer no modelo 3 . Este resultado não era esperado à partida, embora não se possa dizer que constitua uma completa surpresa. Com efeito, há dois factores que podem ter contribuído para ele. Primeiro, como se referiu acima, a propósito das estatísticas descritivas tabeladas no Quadro 2, verifica-se no segundo subperíodo uma menor frequência da divulgação de referências a despesas de I\&D por parte das empresas que não capitalizam I\&D. Segundo, como se viu a propósito da evidência disponível no Quadro 3, a informação quantitativa e qualitativa parecem complementar-se, e o valor desta última parece ser subsidiário daquela outra. Aceitando-se que a evidência do Quadro 4 sugere um incremento do valor informativo da informação quantitativa sobre I\&D no subperíodo 2005-2006, pode aceitar-se também que o contraponto desse aumento é a perda de significância da informação qualitativa. Porém, atendendo ao facto de que a informação qualitativa é não relevante no segundo subperíodo, mesmo quando isoladamente considerada (modelo 2, não tabelado), parece ser de privilegiar o primeiro dos factores referidos - uma menor frequência das divulgações qualitativas - como principal responsável pelos resultados encontrados para REF_I\&D.

Relativamente às hipóteses de investigação, não há uniformidade nas conclusões quando se consideram subperíodos. No que respeita à informação quantitativa (variáveis $S / \& D / C P$ e $I \& D / C P$ ), a $H 1$ verifica-se em ambos os subperíodos (modelos 1 e 2 não tabelados); o mesmo não acontece para a informação de natureza qualitativa (REF_I\&D), em que a $H 1$ não se verifica em 2005-2006, dado o coeficiente da variável no modelo 2 (não tabelado) ser não significativo. Quanto à $H 2$, ela apenas se verifica neste último subperíodo, consubstanciando-se na ausência de valor incremental da variável REF_I\&D.

Em suma, embora o nível explicativo do modelo, apreciado pelo $R^{2}$, não mostre uma evolução muito significativa de um subperíodo para o outro, a evidência discutida sugere que a adopção das NIC por parte das empresas em 2005 terá influenciado a qualidade da informação percebida pelos investidores e, como tal, terá provocado uma (ligeira) alteração na relevância valorativa da informação sobre as despesas de I\&D, com melhoria (deterioração) para a de natureza quantitativa (qualitativa) no subperíodo 2005-2006. A capitalização das despesas de I\&D tende a ser informação mais relevante para os investidores do que a informação de natureza qualitativa disponibilizada pelas empresas nos respectivos relatórios e contas. Esta evidência apresenta semelhanças com as conclusões dos estudos de Callimaci e Landry (2004) e Oswald e Zarowin (2007)

O mencionado impacto da adopção das NIC deve ser ponderado para ter em consideração que o espaço temporal da amostra é ainda demasiado reduzido para se poderem tirar ilações robustas a tal propósito. Porém, mesmo tendo em consideração esta limitação, a evidência recolhida sugere que futuros estudos da relevância informativa das despesas de I\&D devem incluir controlo específico para a alteração ocorrida ao nível do normativo contabilístico vigente.

7 Agradece-se a um referee anónimo a chamada de atenção para o facto de as NIC não terem introduzido a este nível um regime muito diverso do preconizado pela DC 7/92. É um facto, embora pareça ser de considerar que essa directriz não estava a ser aplicada pelas empresas, pelo menos com o rigor imposto pela IAS 38 . Veja-se, por exemplo, a partir do Quadro 2, a diferença dos subperíodos no que respeita ao stock de I\&D e à capitalização de I\&D por exercício: são menores em 2005-2006. Aliás, o maior rigor na aplicação daquela norma relativamente à DC - o enforcement, como atrás se referiu - é também sustentado no facto de $89 \%$ das observações do subperíodo 2000-2004 apresentarem valores da variável SI\&D/CP superiores a zero, enquanto no subperíodo $2005-2006$ somente $34 \%$ das observações desta variável assumem valores positivos. 


\subsubsection{Estimação dos modelos para o sector das novas tecnologias}

É frequente associar às empresas tecnológicas, de informática e comunicações, um maior nível de intangíveis, identificados ou não contabilisticamente, que justificam a maior diferença na relação entre o seu valor de mercado e o respectivo capital próprio. Por exemplo, Chiang e Mensah (2004), num estudo de relevância informativa para uma amostra de empresas de software, consideram as despesas de I\&D um factor crítico de sucesso deste sector.

Neste contexto e complementando os testes estatísticos discutidos até ao momento, testaram-se (valores não tabelados) as hipóteses para o caso concreto do sector das novas tecnologias (CAE 7). Procurou-se aferir se o valor informativo da I\&D deste sector é diferente do encontrado para a amostra global.

Para o período global do estudo (2000-2006) não se verifica qualquer das hipóteses. As variáveis relativas à I\&D, nos três modelos, são não significativas. Tendo em consideração que se trata do sector com maior volume de I\&D, este é um resultado inesperado. Uma possível explicação passa por se considerar que os investidores não atribuem significância valorativa aos valores capitalizados, nem tão pouco à informação de natureza qualitativa, por não confiarem que tais valores se venham a transformar em cash flows futuros. Em favor desta explicação está o facto de se encontrar relevância para a informação quantitativa sobre I\&D quando se replica a análise por subperíodos, mas apenas para o último deles (2005-2006). Esta evidência sugere, pois, como acima se referiu, que a adopção das NIC, e o que daí resultou em termos de rigor para o processo de contabilização e de capitalização da I\&D, veio credibilizar esse tipo de informação. Ou seja, tal adopção produziu efeitos na relevância informativa da I\&D.

\subsection{Testes de robustez}

Com o objectivo de avaliar a consistência dos resultados discutidos anteriormente, efectuou-se um conjunto de testes de robustez de que agora se dá conta.

Entre os principais, referem-se: i) regressão dos modelos com a amostra total, incluindo os outliers; ii) consideração da variável «valor de mercado» (VM) referida ao final do mês de Dezembro do ano a que respeita a informação contabilística; iii) inclusão nos modelos da variável «logaritmo de activo» com o objectivo de controlar para a dimensão da empresa; iv) definição da variável relativa à referência $a$ informação sobre I\&D de modo distinto, nomeadamente não a condicionando, como acontece com REF_I\&D, a que a empresa não capitalize este tipo de despesas no exercício; v) utilização do montante de I\&D capitalizado no exercício (I\&D/CP) como variável a testar, alternativamente ao stock de I\&D capitalizado $(S / \& D / C P)$.

Em termos gerais, a evidência empírica recolhida com estes testes não se distingue qualitativamente da tabelada e discutida anteriormente. A excepção ocorre para o caso em que o VM é referido a Dezembro, situação em que os coeficientes das variáveis $S / \& D / C P$ e I\&D/CP não são significativas no subperíodo 2000-2004. Este resultado, que se considera não colocar em causa as conclusões da análise tabelada, pode ser olhado como mais um elemento corroborativo de que a adopção das NIC terá influenciado a percepção dos investidores relativamente à qualidade da informação sobre I\&D.

Efectuou-se ainda um teste destinado a controlar o impacto das condições do mercado de capitais português no período do estudo ${ }^{8}$. Tendo em consideração a rendibilidade (retorno) anual desse mercado, pode cindir-se o período em análise em dois subperíodos: de 2000 a 2002, foi negativa; de 2003 a 2006, foi positiva. Definiu-se uma variável dummy que reflecte esses subperíodos e foi utilizada para construir variáveis interactivas que reflectem o impacto de tal rendibilidade nas variáveis relativas à I\&D. O Quadro 5 disponibiliza os resultados obtidos. Para facilitar a leitura, as variáveis interactivas utilizadas foram tratadas de modo a que o quadro oferecesse os coeficientes consolidados das variáveis originais para os diferentes estados do mercado. 


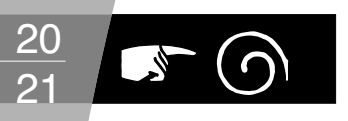

\begin{tabular}{|c|c|c|c|}
\hline \multirow{3}{*}{ Variáveis Independentes } & \multirow{3}{*}{ Sinal esperado } & \multicolumn{2}{|c|}{ Modelo 3} \\
\hline & & Retorno $<0$ & Retorno >0 \\
\hline & & \multicolumn{2}{|c|}{$\begin{array}{c}\text { Coeffic. } \\
\text { (p-value) }\end{array}$} \\
\hline CONSTANTE & ? & \multicolumn{2}{|c|}{$\begin{array}{r}0,612 \\
(0,205)\end{array}$} \\
\hline$R L / C P$ & + & \multicolumn{2}{|c|}{$\begin{array}{r}5,580 \\
(0,000)\end{array}$} \\
\hline$D D$ & ? & \multicolumn{2}{|c|}{$\begin{array}{c}-0,082 \\
(0,773) \\
\end{array}$} \\
\hline$D D^{*} R L / C P$ & - & \multicolumn{2}{|c|}{$\begin{array}{l}-6,177 \\
(0,000)\end{array}$} \\
\hline$S / \& D / C P$ & + & $\begin{array}{l}-4,856 \\
(0,022)\end{array}$ & $\begin{array}{r}1,250 \\
(0,000)\end{array}$ \\
\hline$R E F \_I \& D$ & + & $\begin{array}{r}3,648 \\
(0,000)\end{array}$ & $\begin{array}{r}0,431 \\
(0,098)\end{array}$ \\
\hline \multicolumn{4}{|l|}{$\ldots$} \\
\hline $\begin{array}{l}R^{2} \\
R^{2} \text { ajustado } \\
\text { Teste } F \text { (p-value) } \\
\text { N. Observações }\end{array}$ & & & \\
\hline
\end{tabular}

Definição das variáveis: «Retorno» é a rendibilidade anual do mercado; as restantes variáveis estão definidas no quadro 2 .

Notas: i) Controlou-se para os efeitos fixos de indústria e ano. Por questões de parcimónia, não se tabelam os respectivos coeficientes. Porém, eles são quase sempre não significativos; ii) a amostra contém 235 obs.

Um olhar panorâmico sobre os resultados tabelados permite verificar que o estado do mercado afecta a relevância da informação relativa à I\&D. Quando o mercado está deprimido (período 2000-2002), a informação quantitativa é negativamente valorada, sugerindo a descrença dos investidores quanto ao impacto da I\&D, que assumem ter efeito negativo sobre os cash flows futuros das empresas. Uma potencial explicação para essa descrença pode passar por uma menor qualidade percebida da I\&D capitalizada, fruto da tentativa das empresas em «dourarem» os respectivos resultados nessas alturas. Em favor desta explicação está o facto da informação de natureza qualitativa ser positivamente valorada. No período subsequente, de rendibilidades positivas, a situação é diferente, e mais próxima da tabelada no Quadro 4, com a relevância da informação quantitativa a ter como contraponto a perda de relevância da informação qualitativa.

\section{Conclusão}

Os estudos sobre a relevância informativa das despesas de I\&D, incidindo maioritariamente sobre a realidade anglo-saxónica, apresentam de forma consistente evidência empírica que sugere que o mercado avalia positivamente tais despesas, mesmo quando elas são contabilizadas como um gasto do exercício. Recentemente surgiu evidência empírica de que o modo de contabilização de tais despesas tem impacto na avaliação dos investidores, com a relevância informativa das despesas capitalizadas a ser superior à das que são consideradas como gasto (e.g. Oswald e Zarowin, 2007).

Na mesma linha de investigação, o presente estudo procurou aferir a relevância informativa desse tipo de despesas de I\&D para o contexto português. A metodologia adoptada assentou no uso de modelos econométricos, que tiveram em consideração a natureza da informação 
disponibilizada aos investidores pelas empresas e a alteração do normativo contabilístico em 2005, com a adopção por parte das empresas da amostra das NIC.

A evidência empírica recolhida para o período global da análise sugere que os investidores avaliam positivamente a informação sobre I\&D, quer seja de natureza quantitativa, quer seja qualitativa. Porém, relativamente a esta última, o nível de significância estatística é menor, sugerindo que tal informação é potencialmente menos relevante para os investidores. Mais, o seu valor incremental é nulo quando se consideram, em simultâneo, ambos os tipos de informação.

A alteração do normativo contabilístico em 2005 teve impacto na relevância informativa das despesas de I\&D, ainda que relativamente modesto. A informação de natureza quantitativa tornou-se mais relevante, enquanto a de natureza qualitativa perdeu por completo a relevância que tinha no período pré-2005. Uma melhor qualidade da informação sobre I\&D percebida pelos investidores na sequência da adopção das NIC e a redução das divulgações de natureza qualitativa parecem ser as principais razões explicativas da evidência empírica coligida.

Constatou-se também que o clima vivido no mercado de capitais, traduzido nas rendibilidades anuais proporcionadas aos investidores, também influencia a relevância valorativa da informação sobre I\&D. De modo particular, quando o clima é depressivo e as rendibilidades negativas, os investidores avaliam negativamente o investimento feito anualmente, bem como o acumulado, mas avaliam positivamente a informação de natureza qualitativa. Esta evidência parece traduzir uma descrença dos investidores na qualidade das despesas de I\&D capitalizado pelas empresas nesses períodos.

O presente trabalho contribui em quatro aspectos principais para a literatura da especialidade. É o primeiro estudo de âmbito nacional que se debruça de forma abrangente sobre a relevância valorativa deste tipo de informação no contexto português. O segundo contributo advém do contexto temporal subjacente ao estudo, que considera o período de transição para o normativo do IASB e permite constatar o impacto da alteração do contexto contabilístico. A evidência obtida sugere que este normativo proporcionou um acréscimo de relevância à informação quantificada sobre I\&D capitalizada, mas reduziu a de natureza qualitativa. O terceiro contributo pode ser considerado uma inovação relativamente a outros estudos congéneres (por exemplo, Leote, 2006), e consiste na consideração pelo estudo da informação de natureza qualitativa divulgada. Deste modo se estende o conhecimento sobre a relevância informativa das divulgações relativas às despesas de I\&D. Por último, o estudo testa o impacto do clima do mercado de capitais na relevância valorativa da informação sobre I\&D, o que é, tanto quanto se sabe, uma novidade absoluta neste tipo de investigação.

Pelas contribuições que faz, o estudo é de interesse para a comunidade académica e também para os organismos reguladores, a quem incumbe definir a natureza de informação a divulgar pelas empresas.

Porém, dadas as limitações que Ihe estão subjacentes, este estudo deve ser olhado como primordialmente exploratório. A primeira e principal é a não existência de dados sobre as despesas de I\&D contabilizadas anualmente como gastos pelas empresas. Tal falta, que no caso da presente amostra resulta do não cumprimento por parte destas do preceituado na IAS 38 , tornou impossível conduzir testes que fossem mais directamente comparáveis com os disponíveis na literatura para o universo anglo-saxão. Uma segunda, é o reduzido período da análise pós-2005, que limitou as conclusões sobre o impacto da adopção das NIC.

O presente estudo deixa em aberto, por conseguinte, um manancial de pistas para futura investigação. 
Aboody, D. e Lev, B. (1998) The Value Relevance of Intangibles: The Case of Software Capitalization, Journal of Accounting Research, 36 (3), 161-191.

Amir E., Guan, Y. e Livne, G. (2007) The Association of R\&D and Capital Expenditures with Subsequent Earnings Variability, Journal of Business Finance \& Accounting, 34 (1-2), 222-246.

Brown, S., Lo, K. e Lys, T. (1999) Use of $\mathrm{R}^{2}$ in Accounting and Research: Measuring Changes in Value Relevance over the Last Four Decades, Journal of Accounting \& Economics, 28, 83-115.

Callimaci, A. e Landry, S. (2004) Market Valuation of Research and Development Spending under Canadian GAAP, Canadian Accounting Perspectives, 3, 33-53.

Chiang, C. e Mensah, Y. (2004) The Determinants of Investor Valuation of R\&D Expenditure in the Software Industry, Review of Quantitative Finance \& Accounting, 22 (4), 293-313.

Cockburn, I. e Griliches, Z. (1988) The Estimation and Measurement of Spillover Effects of R\&D Investment, AEA Papers and Proceedings, 78 (2), 419-423.

Core, J., Guay, W. e Buskirk, A. (2003) Market Valuations in the New Economy: An Investigation of What Has Changed, Journal of Accounting \& Economics, 34, 43-67.

Deng, Z., Lev, B. e Narin, F. (1999) Science and Technology as Predictors of Stock Performance, Financial Analysts Journal, 55 (3), 20-32.

Ferreira, L., Isidro, H. e Alves, P. (2001) The Role of Research and Development (R\&D) Capitalization: the Case of Portuguese Listed Companies, Journal for Management Theory and Practice, 24, 45-53.

Fonseca, M. (2001) Enquadramento Contabilístico de Elementos Intangíveis de Natureza Activa, Tese de Mestrado em Ciências Empresariais, Faculdade de Economia da Universidade do Porto. Francis, J. e Schipper, K. (1999) Have Financial Statements Lost Their Relevance?, Journal of Accounting and Research, 37, 319-352.

Green, J., Stark, A. e Thomas, H. (1996) UK Evidence on the Market Valuation of Research and Development Expenditures, Journal of Business Finance \& Accounting, 23 (2), 191-216.

Hayn, C. (1995) The information content of losses, Journal of Accounting and Economics, 20, 125-153.

Hirschey, M. (1982) Intangible Capital Aspects of Advertising and R\&D Expenditures, Journal of Industrial Economics, 375-389.

Hirschey, M.; Weigandt, J. (1985) Amortization Policy for Research and Development Expenditures, Journal of Accounting Research, Spring, 326-335.

Hirschey, M.; Richardson, V. ; Scholz, S. (2001) Value Relevance of Nonfinancial Information: The Case of Patent Data, Review of Quantitative Finance and Accounting, 17, 223-235.

Leitão, P. (2006) Divulgação de Informação sobre as Despesas de Investigação e Desenvolvimento: análise de algumas empresas cotadas em Portugal, Contabilidade e Gestão (Portuguese Journal of Management and Accounting), 2, 87-115.

Leote, F. (2006) Despesas de Investigação e Desenvolvimento e o Valor das Empresas Portuguesas, Tese de Mestrado em Contabilidade e Auditoria, Universidade de Évora.

Lev, B. e Sougiannis, T. (1999) Penetrating the Book-to-Market Black Box: The R\&D Effect, Journal of Business Finance \& Accounting, 26 (3-4), 419-449.

Liu, Q. (2006) How Good Is Good News? Technology Depth, Book-to-Market Ratio, and Innovative Events, Journal Of Accounting, Auditing \& Finance, Summer, 293-321.

Nascimento, V. (2007) Valorização das Despesas de Investigação e Desenvolvimento por Parte dos Investidores, Tese de Mestrado em Contabilidade, ISCTE-Lisboa. 
Ohlson, J. (1995) Earnings, book values and dividends in equity valuation, Contemporary Accounting Research, 11 (2), 661-687.

Oswald, D. e Zarowin, P. (2007) Capitalization of R\&D and the Informativeness of Stock Prices, European Accounting Review, 16 (4), 703-726.

Selto, F. e Clouse, M. (1985) An Investigation of Managers' Adaptations to SFAS No. 2: Accounting for Research and Development Costs, Journal of Accounting Research, 23 (2), 1985.

Silva, S. (2007) Tratamento Contabilístico das Despesas de Investigação e Desenvolvimento: o caso de algumas empresas portuguesas com projectos de investigação e desenvolvimento financiados, Tese de Mestrado em Contabilidade, ISCTE-Lisboa.

Sougiannis, T. (1994) The Accounting Based Valuation of Corporate R\&D, The Accounting Review, 69 (1), 44-68.

Sougiannis, T., Chan, K. e Lakonishok, J. (2001) The Stock Market Valuation of Research and Development Expenditures, Journal of Finance, 56 (6), 2431-2456.

Trabucho, P. (2007) The Determinants of the Decrease in Value Relevance of Accounting Numbers in Portugal, Caderno do Mercado de Valores Mobiliários, 131-168. 